\title{
Eros e Thanatos em "Tempos Sombrios": aspectos da teoria pulsional em diálogo com Stefan Zweig e Hannah Arendt
}

\author{
Eros and Thanatos in "Dark Times": aspects of the drive theory in dialogue with Stefan \\ Zweig and Hannah Arendt
}

\author{
Érica Schlude Wels* \\ Universidade Federal do Rio de Janeiro, \\ Rio de Janeiro, Rio de Janeiro, Brasil
}

\begin{abstract}
Resumo: O presente artigo reflete sobre aspectos ligados à propensão do homem pela destruição e domínio do outro por meio da violência. Nesse sentido, elencamos reflexões sobre os conceitos psicanalíticos de Eros e Thanatos, além de contribuições do pensamento de Hannah Arendt (1987; 1995; 1997), sobretudo o conceito de "Banalidade do Mal"; O mal concretizado pelo nazismo é monstruosamente banal e burocrático, ao mesmo tempo que eficiente e sistemático, levado a cabo por agentes superficiais (LECHTE, 2002). Buscar-se-á estabelecer um diálogo entre esse arcabouço teórico e três novelas do escritor austríaco Stefan Zweig, ele próprio uma vítima declaradamente pacifista do exílio imposto aos escritores judeus no período da Segunda Guerra: “A coleção invisível” (2015, [1924]), “O Livreiro Mendel" (1999, [1929]) e "Xadrez, uma novela" (2015, [1944]) têm a guerra como pano-de-fundo; O presente trabalho objetiva explorar aspectos da chamada "mitologia psicanalítica", campo definido por Freud como obscuro. Além do caráter destruidor intrínseco à natureza humana, como postulado nos textos freudianos que abordam a guerra (1916; 1933, [1932]), destacamos o protótipo da pulsão de morte: compulsão à repetição e ao retorno do inorgânico, movimento regressivo de retorno a um estado anterior (ROUDINESCO; PLON, 1998). Ao explorar a teoria das pulsões em seu dualismo Eros/Thanatos, lançamos luzes sobre o que Arendt define como "Tempos sombrios".
\end{abstract}

Palavras-chave: Banalidade do mal. Eros \& Thanatos. Pulsão de Morte. Stefan Zweig.

\begin{abstract}
This article reflects on aspects related to the propensity of man for the destruction and domination of the other through violence. In this sense, reflections are emphasized on the psychoanalytic concepts of Eros and Thanatos, besides of the contributions from Hannah Arendt (1987; 1995; 1997), especially with her concept of the banality of evil: The evil made by Nazism is monstrously banal and bureaucratic, at the same time efficient and systematic, carried out by superficial and ordinary people. (LECHTE, 2002). A dialogue will be establish between this theoretical framework and three novels by the Austrian writer Stefan Zweig, which declared himself a pacifist victim of exile imposed on Jewish writers during the Second World War: The Invisible Collection (1999, [1924]), Buchmendel (1999, [1929]) and The Chess Story (2015, [1944]) use war as a background. The present work targets to explore aspects of the so-called "psychoanalytic mythology", a field defined by Freud as obscure. Besides the destructive character intrinsic to human nature, as postulated in the Freudian texts dealing with the war (1916, 1933, [1932]), the prototype of the death drive is being contrasted: Repetition compulsion and the return of the inorganic, the regressive movement of return to an earlier state (ROUDINESCO; PLON, 1998). Exploring the drive theory in its dualism Eros/Thanatos, we light up of what Arendt defined as "Dark Times".
\end{abstract}

Keywords: Banality of Evil. Eros \& Thanatos. Death Drive. Stefan Zweig.

* Professor Adjunto de Língua e Literatura Alemã, Departamento de Letras Anglo-Germânicas, Setor de Língua e Literatura Alemã, Faculdade de Letras (UFRJ - Universidade Federal do Rio de Janeiro, RJ, Brasil). E-mail: schludew@gmail.com. 
Realmente, vivemos tempos muito sombrios!/A inocência é loucura. Uma fronte sem rugasdenota insensibilidade./ Aquele que ri ainda não recebeu a errível notícia / que está para chegar (BRECHT, 1948).

O objetivo do presente artigo é traçar um paralelo entre os tempos sombrios que simbolizam a guerra, as análises empreendidas por Hannah Arendt, e textos freudianos acerca da teoria pulsional, os quais estabelecem a dicotomia Eros \& Thanatos. Para tanto, a metáfora das sombras, e seu contrário, as luzes, é destacada também no ensaio freudiano "Além do Princípio do Prazer" (1996 [1920]). Como diálogo com a literatura, destacamos três contos de Stefan Zweig que versam sobre a guerra, "A Coleção Invisível" (1999, [1924]), “O Livreiro Mendel” (1929, [2015]) e "Xadrez, uma Novela” (2015, [1944]). Em linhas gerais, as obras selecionadas tratam da memória (e a literatura, ou a arte) como resistência possível contra a transitoriedade já preconizada por Freud (1916 [1920]; (1933 [1920]).

Em "Homens em tempos sombrios", Arendt analisa alguns dos representantes de uma época, isto é, porta-vozes do Zeitgeist:

A história conhece muitos períodos de tempos sombrios, em que o âmbito público se obscureceu e o mundo se tornou tão dúbio que as pessoas deixaram de pedir qualquer coisa à política além de que mostre a devida consideração pelos seus interesses vitais e liberdade pessoal. (ARENDT, p. 20, 1987)

Arendt (1987, p. 7), ao analisar os horrores do século passado, afirmava que os "tempos sombrios não são novos" e "não constituem uma raridade na história". No entanto,

[...] mesmo no tempo mais sombrio temos o direito de esperar alguma iluminação, e que tal iluminação pode bem provir, menos das teorias e conceitos, e mais da luz incerta, bruxuleante e frequentemente fraca que alguns homens e mulheres, nas suas vidas e obras, farão brilhar em quase todas as circunstâncias e irradiarão pelo tempo que lhes foi dado na terra (Idem).

Eichmann em Jerusalém (ARENDT, 1999) é resultado de um relato sobre o processo e o julgamento do nazista Adolf Eichmann, realizado em Jerusalém em 1961 e considerada a obra mais polêmica de Hannah Arendt. A crítica da filósofa à conduta das lideranças judaicas nos Estados Unidos, à época do Holocausto, isolou-a da comunidade judaica foi acusada de falta de amor pelo povo judeu.

Nessa obra, encontra-se o conceito de "Banalidade do mal": nem sempre as pessoas que cometeram grandes crimes são grandes criminosos. À luz desse "réu estranho" [Eichmann], como observa Arendt (1999), o mal torna-se um fenômeno político e ético, e não ontológico. Trata-se de um hosti humani generis (inimigo do gênero humano), participante de um novo tipo de crime: assassinatos em massa num sistema totalitário marcado pela burocracia. Nessa função, ele é um mero executor, e não o responsável. A normalidade do réu levou a filósofa a buscar as origens do mal como possibilidade da liberdade humana. 
Para Andrade (2010), foi justamente esse abismo entre a gravidade dos atos e a superficialidade das motivações que levou ao conceito de "banalidade do mal"; o ineditismo do mal efetivado pelo nazismo era, além de monstruoso, banal e burocrático, sistemático e eficiente. Banalidade aqui não é normalidade, tampouco inocência. Nesse sentido, o verdadeiro horror do totalitarismo está no servilismo de seus agentes. O servilismo toma o lugar do valor supostamente moral do totalitarismo. Tal como no lema nazista, "Minha honra é minha lealdade".

Segundo Laufer (1987), os relatos Arendtianos buscam refletir sobre as pessoas no mundo, e não sobre o mundo nas pessoas. Nesse sentido, a Condição Humana (1991), destaca que a ação e o discurso são os modos pelos quais os seres humanos se revelam uns aos outros, na teia das relações intersubjetivas. As histórias, resultado da ação e do discurso, desvendam o sujeito - ninguém é o autor de sua própria vida, mas sim, seu sujeito. "Toda vida humana, compreendida entre o nascimento e a morte, constitui uma história, que se insere na História - livro de muitos autores e narradores, mas sem autores tangíveis.” (ARENDT, 1991, p. 235)

Arendt defende que a sociedade, em todos os seus níveis, exclui a possibilidade de ação, que antes pertencia ao lar doméstico. Ao invés da ação, a sociedade espera de cada um dos seus membros um certo tipo de comportamento, impondo inúmeras e variadas regras, todas elas destinados a "normalizar" os seus membros, a fazê-los "comportaremse", a abolir a ação espontânea ou a reação inusitada.

Segundo Arendt (1999), o contraste entre o heroísmo israelense e a passividade submissa com que os judeus marcharam para a morte - chegando pontualmente nos pontos de transporte, andando sobre os os próprios pés para os locais de execução, cavando os próprios túmulos, despindo-se e empilhando caprichosamente as próprias roupas, e deitando-se lado a lado para ser fuzilados - parecia uma questão importante, e o promotor, ao perguntar à testemunha após testemunha "Por que não protestou?", "Por que embarcou no trem?”, "Havia 15 mil pessoas paradas lá, com centenas de guardas à frente - por que vocês não se revoltaram, não partiram para o ataque?”, tornava a questão ainda mais difícil de ser respondida. Dezesseis anos antes, ainda sob o impacto dos acontecimentos, David Rousset, ex-prisioneiro de Buchenwald, descrevia o que sabemos ter acontecido em todos os campos de concentração: "O triunfo da SS exige que a vítima torturada permita ser levada à ratoeira sem protestar, que ela renuncie e se abandone a ponto de deixar de afirmar sua identidade. É não é gratuitamente, nem por mero sadismo, que os homens da SS desejam sua derrota. Eles sabem que o sistema que consegue destruir suas vítimas antes que elas subam ao cadafalso... é incomparavalmente melhor para manter todo um povo em submissão. Nada é mais terrível do que essas procissões de seres humanos marchando como fantoches para a morte".

A corte não recebeu nenhuma resposta para essa questão tola e cruel, mas qualquer um poderia facilmente encontrar uma resposta ao lembrar-se do destino daqueles judeus holandeses que, em 1941, ousaram atacar um destacamento da Polícia de Segurança Alemã. Quatrocentos e trinta judeus foram mortos em represália e torturados até a morte, primeiro em Buchenwald, depois no campo austríaco de Mauthausen. Durante meses sem fim, morreram milhares de mortes, e todos eles deviam invejar seus irmãos que 
estavam em Auschwitz e até em Riga e Minsk. Há muitas coisas consideravelmente piores do que a morte. A glória do levante do gueto de Varsóvia e o heroísmo dos poucos que reagiram estava precisamente no fato de eles terem recusado a morte fácil que os nazistas lhes ofereciam - diante do pelotão de fuzilamento ou na câmara de gás. E as testemunhas que em Jerusalém depuseram sobre a resistência e a rebelião e sobre o "lugar insignificante que desempenharam na história do holocausto" confirmaram mais uma vez o fato de que só os muitos jovens haviam sido capazes de tomar "a decisão de não ir para o sacrifício como carneiros". (ARENDT, 1999, 23)

E, em seguida, a respeito do destino, não dos judeus aprisionados nos campos, mas sim de seus juízes e algozes, membros da SS, militares, integrantes da imensa teia de atores do Regime Nazista, Arendt denuncia a mesma passividade de judeus e alemães no ocultamento dos criminosos:

[...] Estima-se que dos 11.500 juízes da Bundesrepublik, 500 estavam ativos nas cortes sob o regime de Hitler. [...] Seja como for, não há dúvida de que o julgamento de Eichmann teve sua consequência de maior alcance na Alemanha. A atitude do povo alemão quanto ao seu próprio passado, sobre a qual os especialistas na questão judaica haviam se debruçado durante quinze anos, não poderia ter sido demonstrada com mais clareza: as pessoas não se importavam com o rumo dos acontecimentos e não se incomodavam com a presença de assassinos à solta no país, uma vez que nenhuma delas iria cometer assassinato em sua própria vontade." (ARENDT, 1999, p. 27).

As críticas de Hannah Arendt ao comportamento moral de judeus e alemães tiveram como objetivo desconstruir algumas argumentações vigentes à época, que tentavam explicar o fracasso moral vivenciado na Europa daqueles tempos sombrios. Dentre tais argumentações, destacaremos três: 1) a teoria da peça de engrenagem; 2) a teoria da culpa coletiva; e 3) a teoria da voz da consciência. A teoria da peça de engrenagem foi utilizada tanto pela defesa de Eichmann quanto pela acusação. Segundo a defesa, Eichmann era apenas uma pequena engrenagem na maquinaria chamada solução final para a questão judaica. A promotoria, seguindo a mesma lógica, via naquele homem não uma engrenagem, mas o motor do Holocausto. Para Arendt, aquele homem tolo, sem iniciativa, medíocre e superficial, oficial subalterno, que sempre agia ancorado por leis e memorandos, não era motor de coisa alguma. No entanto, ela estava de acordo com o que, para as ciências políticas, era importante de entender: "[que] a essência do governo totalitário, e talvez a natureza burocrática, seja transformar homens em funcionários e meras engrenagens, assim os desumanizando" (ARENDT, 1999, p. 312). E esse era um tema ético central à problemática, pois a responsabilidade pessoal não pode ser transferida para um sistema, ainda que se trabalhe sob uma ditadura. Ao rebater essa teoria, a autora insiste na liberdade que caracteriza fundamentalmente a ação humana, que funda e exige toda e qualquer formação moral. "Eichmann se considera culpado perante Deus, não perante a lei" (Idem, p. 32). No tribunal, Eichmann declarou-se "inocente no sentido da acusação", mas também disposto a "ser enforcado publicamente como exemplo para todos antissemitas da terra" (Idem, p. 36). A vocação de Eichmann para o martírio revelou-se depois de ele saber que setores da juventude alemã, motivados possivelmente pela repercussão dos 
resultados dos julgamentos de Nuremberg, se sentiam culpados pelo Holocausto (argumento 2, a teoria da culpa coletiva).

A terceira teoria - a voz da consciência - questionava se Eichmann tinha consciência do que estava fazendo. Para Arendt (1999, p. 45), o réu "não tinha tempo, e muito menos vontade de se informar adequadamente, jamais conheceu o programa do Partido [Nacional Socialista], nunca leu Mein Kampf'. O ponto mais importante não é sobre a consciência no sentido de ter conhecimento do que efetivamente era o nazismo em suas ideologias e programas. O ponto fundamental é se Eichmann podia ouvir essa voz que chamamos de consciência, se ele podia acessar um conjunto de valores morais que lhe informasse sobre o horror do qual ele fazia parte:

A triste verdade acerca do behaviorismo e da validade de suas "leis" é que quanto mais pessoas existem, maior é a possibilidade de que tolerem o não-comportamento. Estatisticamente, isto resulta num declínio da flutuação. Na realidade, os feitos perderão cada vez mais a sua capacidade de opor-se à maré do comportamento, e os eventos perderão cada vez mais a sua importância, isto é, a sua capacidade de iluminar o tempo histórico. (ARENDT, 1991, p. 51).

Além do princípio do prazer (1920), um dos textos mais importantes da chamada "Metapsicologia" Freudiana, aborda, em dois momentos, a metáfora das luzes e das sombras $^{1}$ : Freud fala da obscuridade em que se encontra mergulhada a teoria das pulsões ${ }^{2}$, assim como no escuro em que se encontra a ciência, que, diante das pulsões e dos desejos humanos, oferece poucas explicações; estas podem ser melhor fornecidas por meio de dois mitos - o conhecido "Mito do Andrógeno", na fala de Aristófanes, ou na leitura dos Upanishadas ${ }^{3}$, situados como possível fonte ao pensamento platônico, datando de uma data posterior a 800 a.C.

Esse conhecido artigo reformula a dualidade da teoria pulsional, a partir de um recorte topográfico (e não mais qualitativo), e situa a fuga do desprazer como mola mestre do psiquismo humano.

No início de seu texto, configurando a "Pulsão de Morte", Freud menciona a "neurose traumática", como dos ex-combatentes, semelhante à histeria. A fixação no momento do trauma e a afirmação de que os histéricos sofrem de reminiscências (FREUD, 1996, [1920], p. 23) leva a um quadro no qual a cura é constantemente ameaçada, escurecida por "misteriosas tendências masoquistas do ego".

Segundo Mezan (1985), Thanatos é introduzido em "Além do Princípio do Prazer", na forma de uma especulação que procura dar conta de uma série de fenômenos. Essa concepção inicial (ainda incerta naquela obra) torna-se o ponto central de "O Mal Estar

\footnotetext{
${ }^{1}$ No original alemão, tais passagens são definidas pelo adjetivo "dunkel”, isto é, "escuro".

2 Aqui, utilizamos o termo "pulsão", ao invés de "instinto".

3 Os Upanixades, também grafados Upanishads, Upanissades e Upanichades são parte das escrituras Shruti hindus, que discutem principalmente meditação e filosofia, e que são consideradas pela maioria das escolas do hinduísmo como instruções religiosas. Contêm também transcrições de vários debates espirituais, e 12 de seus 123 livros são considerados básicos por todos os hinduístas. Estas obras se tornaram conhecidas no mundo ocidental, pela primeira vez, no início do século XIX, através de uma tradução feita do Persa para o Latim, que influenciou fortemente o pensamento do filósofo alemão Arthur Schopenhauer.
} 
na Civilização", de 1929, constituindo uma qualidade específica que define a pulsão como tal, isto é, sua tendência regressiva. Assim, a repetição abarca a tendência a reviver situações penosas, especialmente ligadas aos traumas infantis, observável durante o trabalho de análise, situações que permanecem enigmáticas quando analisadas à luz da atualidade e que se explicam por meio da noção de "retorno do reprimido". Trata-se do fundamento mesmo da terapia analítica; o conflito reprimido, ao se atualizar na relação transferencial, surge sob uma nova perspectiva e comporta soluções diferentes das adotadas na época em se apresentou pela primeira vez. Freud busca na origem da vida o primeiro produtor de tensões, de modo que a tendência à descarga se revela como aspiração do inorgânico. "Parece, então, que um instinto é um impulso, inerente à vida orgânica, a restaurar um estado anterior de coisas [...].” (FREUD, 1996, [1920], p. 46). Se tomarmos como verdade o fato de que todo organismo deve morrer por razões internas, tornando-se mais uma vez inorgânico, temos a máxima de que "o objetivo de toda vida é a morte" e que "as coisas inanimadas existiram antes das vivas" (FREUD, 1996, [1920], p. 48). Assim, a noção inicial, que opunha as pulsões do ego às do objeto, a partir dos versos de Schiller, "são a fome e o amor que governam o mundo" cede lugar à nova dualidade Eros versus Thanatos, sendo ambos parte do movimento vital. Inicialmente, as pulsões do ego destinam-se à manutenção da espécie, como a procriação, sendo, assim, alinhadas a um sentimento de raízes biológicas, como a fome; por extensão, as pulsões do objeto alinham-se ao amor, em sua busca por completude. "Dessa maneira, a libido de nossos instintos sexuais coincidiria com o Eros dos poetas e dos filósofos, o qual mantém unidas todas as coisas vivas." (FREUD, 1996, [1920], p. 59)

De acordo com Mezan (1985, p. 442) o que há de audacioso na visão Freudiana é a vinculação desse mecanismo pulsional com a esfera biológica, ultrapassando o nível propriamente psíquico. Com isso, a pulsão, que deve ser entendida como entidade limítrofe entre o psíquico e o orgânico, ganha amplitude, vinculando-se não só ao humano, como à totalidade do reino da vida. "[...] se toda pulsão visa restaurar o estado de quietude, e se a quietude do inorgânico é perturbada pela irrupção da vida, então o retorno à quietude é um retorno à não-vida, e a pulsão é um esforço para atingir a morte." (MEZAN, 1985, p. 442)

Em Por que a guerra? (1933 [1932]), Freud retoma a dualidade das pulsões, diferenciando-as num grupo destinado a preservar e unir ("eróticos", retomando a noção platônica da nostalgia pela unidade perdida) e outro que tende a destruir a matar (agressivo ou destrutivo):

[...] os fenômenos da vida surgem da ação confluente ou mutuamente contrária de ambos. Ora, é como se um instinto de um tipo dificilmente pudesse operar isolado; está sempre acompanhando - ou, como dizemos, amalgamado - por determinada quantidade do outro lado, que modifica o seu objetivo. Assim, por exemplo, o instinto de autopreservação certamente é de naureza erótica; não obstante, deve ter à sua disposição a agressividade, para atingir seu propósito. Dessa forma, também o instinto de amor, quando dirigido a um objeto, necessita de alguma contribuição do instinto de domínio , para que obtenha a posse desse objeto (FREUD, 1933 [1932]), p. 203). 
Em "Sobre a Transitoriedade", enquanto caminha ao lado de um jovem poeta melancólico, e já famoso (Rainer Maria Rilke), Freud o estimula a acreditar na beleza das coisas, cuja significância estaria ameaçada pela violência exacerbada da guerra. "Uma flor que dura apenas uma noite nem por isso nos parece menos bela." (1933 [1932]), p. 318) $\mathrm{Na}$ verdade, esse curto, porém pungente texto freudiano retoma a visão psicanalítica do luto, questionando o porquê de o desligamento da libido de seus objetos constituir um processo tão penoso. O luto chegaria a um fim espontâneo renunciando a tudo que perdeu e consumindo-se a si próprio, libertando a libido para novamente buscar objetos "igualmente preciosos".

É de se esperar que isso também seja verdade em relação às perdas causadas pela presente guerra. Quando o luto tiver terminado, verificar-se-á que o alto conceito em que tínhamos as riquezas da civilização nada perdeu com a descoberta de sua fragilidade. Reconstruiremos tudo o que a guerra destruiu, e talvez em terreno mais firme e de forma mais duradoura do que antes (FREUD, 1933 [1932]), p. 319).

Escritor austríaco de ascendência judaica, conhecido pelo suicídio ocorrido em Petrópolis, Rio de Janeiro, Stefan Zweig (1881-1942) figura certamente entre os autores de língua alemã mais lidos e traduzidos no Brasil; para a Germanística, além de novelista e contista de obra extensa, reconhecida por público e crítica, é um dos principais nomes da chamada "Literatura de exílio". No período de sua morte, em 1942, Zweig deixa três obras importantes, entre elas, a Schachnovelle, em português, Uma partida de xadrez ou, em tradução mais recente, Xadrez, uma novela. Nela, um ex-prisioneiro da Gestapo, confinado num hotel, escapa da loucura lendo e relendo um pequeno manual de xadrez que fora furtado do bolso do sobretudo de um oficial alemão. A guerra, dessa vez a Primeira, é o pano de fundo das duas outras novelas citadas no presente trabalho: A coleção invisivel (ZWEIG, 1999, [1924]) e O Livreiro Mendel (ZWEIG, 1999, [1929]). As conseqüências da hiperinflação alemã na vida de uma família burguesa, no primeiro, e os efeitos devastadores do anti-semitismo entre vítimas indefesas, como um humilde comerciante de livros, no segundo.

Em O Livreiro Mendel, o narrador busca abrigo da chuva e adentra um velho café, o qual lhe provoca uma onda automática de reminiscências. Homenageando a tradicional cultura vienense dos cafés, o conto tem como aspecto principal o ritmo movediço da memória. "Mas sim, sim, eu estivera aqui uma vez há vinte anos ou mais, pois oculto no invisível como o prego na madeira havia algo de mim há muito esquecido.” (ZWEIG, 1999 , p. 202). Por fim, como uma "claridade fosforecente, trêmula e cintilante", vem à luz o nome de Jakob Mendel, o Livreiro Mendel em seu "quartel-general”, o Café Gluck. A relação de Mendel com os livros (ele conserva em sua memória prodigiosa os preços e títulos dos livros raros que comercializa, a exemplo de um catálogo abismal) é descrita como sagrada:

Pois lia como outros rezam, como jogadores jogam e como bêbados olham obstusamente o vazio, lia com uma concentração tão comovente que desde então o jeito de ler de todas as outras pessoas sempre me pareceu profano (ZWEIG, 1999, p. 205). 
A guerra é, portanto, o ponto que desarticula o passado e o presente, interferindo na vida desse judeu da Galícia, barbudo e corcunda, mas real "titã da memória” (ZWEIG, 1999, p. 209).

No centro da censura dos militares, enquanto toda a correspondência com o exterior era interceptada, um oficial tem nas mãos um cartão-postal de Mendel, endereçado a outro livreiro, residente em Paris. O censor supõe que se trata de mensagem cifrada, suspeita. Algumas semanas depois, novo cartão-postal de Jakob Mendel é interceptado, desta vez com destino a Londres, levando os oficiais a buscarem o suspeito em seu local de trabalho, isto é, a velha mesa de mármore do Café Gluck. Durante o interrogatório, no qual outra língua, que não a dos livros, é utilizada, Mendel complica sua frágil situação de judeu nascido na Rússia, sem permissão oficial para exercer o trabalho de vendedor ambulante e sem cidadania austríaca. Para os oficiais, não resta opção mais adequada do que encaminhar o livreiro a um campo de concentração de prisioneiros, metido em um fino paletó de verão. Durante dois anos, separado de seus amados livros, com seus óculos destruídos, Mendel é reduzido a tornar-se uma "toupeira cinzenta, sem olhos e muda" (ZWEIG, 1999, p. 226). Em 1917, consegue a libertação, por intermédio de um grupo de clientes influentes e fiéis. Retornando ao Café Gluck, "ele não era o mesmo, não era mais o miraculum mundi, o registro mágico de todos os livros" (ZWEIG, 1999 , p. 227). Por fim, mesmo com o término da guerra, o livreiro se vê enfrentando novo horror, dessa vez a pobreza. Com menos clientes, falta dinheiro para pagar pelo pão e pelo café de todos os dias, e aos poucos, com a compra do estabelecimento por um novo dono, o qual não admite a presença indesejável do homenzinho, ele termina na rua; tenta, uma vez mais, retornar ao café, caindo no chão, inconsciente, sendo encaminhado em seguida ao hospital, onde morre.

À parte desse engenhoso enredo, Zweig faz uso da metáfora dos livros para discorrer sobre a impossibilidade da arte, da delicadeza e da memória, num mundo revirado pela violência da guerra. O Livreiro Mendel simboliza a própria literatura, silenciada ou impossibilitada de se expressar; restam somente o trauma e a violência. A lição do conto é ilustrada nas palavras finais, quando o narrador lamenta o esquecimento daquele homem, que nenhum livro esquecia e que carregava dentro de si a maior de todas as bibliotecas: "[...] eu esquecera o Livreiro Mendel anos a fio, logo eu que devia saber que a gente só cria livros para ligar-se a outras pessoas e defender-se contra a implacável contraparte de toda a vida: a transitoriedade e o esquecimento.” (ZWEIG, p. 1999, 234)

A memória é novamente o fio condutor da trama de "A Colecao Invisível",publicada originalmente em 1925 e talvez a única experiência literária inspirada num evento macroeconômico", o que já se percebe pelo subtítulo "um episódio da inflação alemã". O mote desse relato é a diluição de valores provocada pela inflação fulminante dos primeiros anos da República de Weimar (1919-1933), a partir de um drama familiar trágico e antagônico: a paixão de colecionador, um ancião cego, ferido durante a Guerra Franco-Prussiana (1870-71), incapaz de verificar o que sua esposa e filha fizeram com seu volumoso acervo de gravuras. 
O senhor sem dúvida está ciente da atual situação do comércio de objetos de arte, desde que o valor do dinheiro foi literalmente pelos ares: os novos-ricos de subúrbio passaram a se entusiasmar por madonas góticas, incunábulos, velhas estampas, quadros, nada é suficiente para eles; precisamos inclusive ficar atentos para que não nos esvaziem a casa e as gavetas. (ZWEIG, 2015, p. 161)

Esses aspectos parecem evocar alguma coisa de autobiográfico, uma vez que o escritor testemunhara os anos de hiperinflação, assim como era possuidor de uma valiosa coleção de manuscritos, iniciada em seus tempos de adolescente. Como muitas novelas de Zweig, o narrador-participante apresenta ao leitor aspectos do que vivenciara e o marcara profundamente: tudo é narrado durante uma viagem ferroviária do antiquário que tentara, outrora, comprar parte da coleção. De passagem por uma pequena cidade da Saxônica, proveniente de Berlim, o antiquário decide visitar um velho cliente do negócio de família. $O$ ancião o recebe calorosamente, enquanto o narrador experimenta imediatamente grande tensão entre as personagens do modesto apartamento.

Isso é realmente muito amável da sua parte. Asseguro que o senhor não terá feito a viagem em vão. Há de admirar algo que não se pode ver todo dia, nem mesmo na sua opulenta Berlim, algumas estampas como nem no Albertina ou na maldita Paris se encontrará mais belas. É. Quando se coleciona sessenta anos a fio acaba-se selecionando objetos que não se encontra em qualquer esquina. Louise, me dê a chave do armário! (ZWEIG, 2015, p. 165)

Até que a filha do velho militar consegue encontrá-lo no hotel, de onde o levaria para a visita. Lá, narra ao antiquário o drama da família, cujas necessidades financeiras causadas na luta pela sobrevivência levaram ao consumo das belas gravuras. Assim como em O Livreiro Mendel, a arte (na primeira novela temos explicitamente os livros e a literatura) é um testemunho da beleza da vida, a qual perece inexoravelmente diante da violência dos tempos sombrios da guerra, tempos de absoluta privação. A memória é novamente o que assegura o valor das coisas que resistem ao tempo, como a arte, mesmo quando ela própria se torna moeda de troca no mercado, gerando mais riqueza para alguns e garantindo somente a sobrevivência de outros. A coleção viveria enquanto vivesse o colecionador, pois dentro dele ela permaneceria protegida dos arroubos do mundo externo:

Um calafrio me percorreu a espinha enquanto ele enaltecia assim animado um papel completamente em branco. E era fantasmagório acompanhar como ele apontava com a unha do indicador, numa precisão milimétrica, todos os invisíveis carimbos dos colecionadores que continuavam a existir apenas em sua imaginação. Com a garganta apertada pelo horror, eu não sabia o que responder. Mas quando, confuso, olhei para ambas as mulheres trêmulas e ansiosas, percebi de novo suas mãos suplicantes erguidas. (ZWEIG, 2015, p. 170)

Finalmente, em Xadrez, uma Novela (Schachnovelle, isto é, "novela de xadrez”), dá-se o único confronto de Zweig com o nazifacismo, trazendo à tona um enredo de impacto, marcado pelo antitotalitarismo e pacifismo, tendências, aliás, presentes no posicionamento ideológico do escritor. Um dos aspectos mais importantes é que esta 
novela foi produzida em Petrópolis, RJ, entre 1941 e meados de fevereiro de 1942. Bebendo nas fontes de seu fascínio pelo jogo e pela complexa dinâmica do tabuleiro de xadrez, Zweig transforma a narrativa numa espécie de epílogo, pois esta é sua derradeira obra antes da carta de despedida deixada no cenário de seu suicídio e simplesmente intitulada "Declaração".

Dr. B, prisioneiro da Gestapo, é torturado psicologicamente durante meses, permanecendo encarcerado num quarto de hotel. A fim de ocupar a mente e não sucumbir à pressão dos agentes que o interrogam com regularidade, decora as 150 mais famosas partidas de xadrez do manual que conseguira furtar.

Depois de mais quinze dias, eu era capaz de jogar cada partida do livro de cor - ou como dizem no jargão especializado, às cegas. Só então comecei a compreender que benção inaudita o meu furto ousado me proporcionara. Pois de repente eu tinha uma atividade sem sentido, sem função, se quiser, mas uma atividade que aniquilava o nada à minha volta. (ZWEIG, 2015, p. 257)

Quando solto, escapa da Áustria nazificada e chega aos Estados Unidos, onde embarca num luxuoso navio que faz o percurso Buenos Aires-Nova Iorque. Ao companheiro de viagem e agora narrador, o advogado relata como resistira aos interrogatórios. No navio, encontra-se o campeão mundial Mirko Czentovi, que fará algumas apresentações em Buenos Aires para o público de enxadristas. O campeão é pintado como um robô, homem rude e sem atrativos, e que é convencido a jogar uma partida contra um pequeno grupo de passageiros. Tudo indica que o enxadrista caminha para mais um xeque-mate, senão fosse a inesperada participação do Dr. B no comando de adversários. Este ganha com maestria a primeira partida e torna-se presa de grande excitação e descontrole. No final, desiste do jogo e retira-se de cena:

Ele acenou com a cabeça e saiu, de maneira simples e misteriosa, assim como surgira. Só eu sabia por que aquele homem nunca mais tocaria num tabuleiro, enquanto os outros ficaram um pouco confusos, com a vaga sensação de, por um triz, terem escapado a algo muito mais agradável e perigoso (ZWEIG, 2015, p. 274).

A dificuldade de classificar o mal nazista, eficiente, burocrático, e seus personagens, como Adolf Eichmann, leva Hannah Arendt a criar o conceito de "Banalidade do Mal", a maldade que apresenta o rosto assustadoramente comum de um funcionário público. A metáfora de "tempos sombrios" remete automaticamente ao colapso civilizatório provocado pela II Guerra e o Holocausto, além de indicar um pouco do sofrimento infligido a todas as suas vítimas.

Antes de Hannah Arendt, Sigmund Freud já definira Thanatos, a "Pulsão de Morte". Exploramos aspectos das teorias freudianas que procuram situar esse lado sombrio do psiquismo como inerente a todos os organismos vivos, em permanente conflito com Eros. As ideias de Freud também devem seu desenvolvimento às dificuldades vivenciadas durante a Primeira Guerra, sobretudo à experiência com pacientes que apresentam severas neuroses de guerra. 
$\mathrm{Na}$ literatura, três novelas de Stefan Zweig ilustram os conceitos apresentados anteriormente. A Primeira Guerra é a fonte do desespero e da miséria vividos pelas personagens, tanto em "O Livreiro Mendel”, quanto em "A Coleção Invisível”. Em ambas as novelas, a memória é o fio que guia o narrador-personagem em seus relatos. Assim, a memória recebe o status de tesouro humano, pois só ela garante a preservação da arte, algo perente, diante do esfacelamento provocado pela violência da guerra. Em "Xadrez, uma Novela", o relato resgata das sombras do passado da Áustria nazista um advogado que sobrevive às torturas psicológicas realizadas pela Gestapo. Sua sobrevivência fora garantida pelo inusitado furto de um manual de xadrez. Encarcerado num quarto de hotel, a memória forçada dos estrategemas das maiores partidas de xadrez do mundo salva o prisioneiro da morte e da loucura. Anos mais tarde, a caminho de Nova Iorque em um luxuoso transatlântico, desafia, juntamente com alguns passageiros audaciosos, um grande campeão de xadrez. Sua vitória deixa a todos perplexos, inclusive o próprio oponente, mas é acompanhada de uma falência nervosa, à medida que o jogo avança para o seu desfecho. A disputa no presente reavivara o trauma sofrido, ferida permanentemente aberta.

Dessa forma, procuramos reunir aspectos teóricos e literários ligados à experiência da guerra, reafirmando como salvação possível o humano no que ele tem de mais próprio: sua capacidade de lembrar e dar sentido à sua existência.

\section{REFERÊNCIAS}

ARENDT, Hannah. Homens em tempos sombrios. Acrescido de um perfil de Hannah Arendt por Celso Lafer. Trad. Denise Bottmann: São Paulo: Companhia das Letras, 1987.

- A Condição bumana. Trad. Roberto Raposo. Posfácio de Celso Lafer. 5. ed. Rio de Janeiro: Forense Universitária, 1991.

A vida do espirito: o pensar, o querer, o julgar. Trad. Antônio Abranches, César

Augusto R. de Almeida, Helena Martins. Rio de Janeiro: Relume Dumará, 1993.

. Eichmann em Jerusalém. Trad. José Rubens Siqueira. Sao Paulo: Companhia das Letras, 1999.

- Origens do Totalitarismo. São Paulo: Companhia do Bolso, 2012.

ANDRADE, Marcelo. A banalidade do mal e as possibilidades da educação moral: contribuições arendtianas. Disponível em: http://www.scielo.br/pdf/rbedu/v15n43/a08v15n43.pdf Revista Brasileira de Educação v. 15 n. 43 jan./abr. 2010.

FREUD, Sigmund. Sobre a transitoriedade. (1916 [1915]). Obras Psicológicas completas de Sigmund Freud: Edição Standard Brasileira. Rio de Janeiro: Imago, 1996. Vol. XIV. 
- Além do princípio do prazer. (1920). Obras Psicológicas completas de Sigmund Freud: Edição Standard Brasileira. Rio de Janeiro: Imago, 1996. Vol. XVIII.

. Por que a guerra?. (1933 [1932]). Obras Psicológicas completas de Sigmund Freud: Edição Standard Brasileira. Rio de Janeiro: Imago, 1996. Vol. XXII.

MEZAN, Renato. Freud, o Pensador da Cultura. 3. ed. Sao Paulo: Ed. Brasiliense, 1985.

ZWEIG, Stefan. O Livreiro Mendel. In: Medo e outras histórias. Trad. Lya Luft. Uma homenagem de Abraão Koogan à memória de S. Zweig. Rio de Janeiro: Record, 1999. 199-234.

- A coleção invisivel. In: Novelas insólitas. Tradução Kristina Michahelles. Rio de Janeiro: Jorge Zahar Editor, 2015.

Xadrež uma novela. In: Novelas insólitas. Tradução Kristina Michahelles. Rio de Janeiro: Jorge Zahar Editor, 2015.

Recebido em: 31/03/2017 Aprovado em: 26/05/2017 Publicado em: 01/06/2017 